\title{
Hypothermia during percutaneous coronary intervention in comatose survivors of cardiac arrest
}

MARKO NOC $(\bowtie)$ Center for Intensive Internal Medicine University Medical Center Zaloska 7. 1000 Ljubljana Slovenia-EU

Phone: + 38615223790

Fax: +3861522 2296

E-mail: marko.noc@mf.uni-lj.si

\section{MARKO NOC}

\begin{abstract}
Urgent invasive coronary strategy including coronary angiography and percutaneous coronary intervention (PCl) is feasible and safe in combination with mild induced hypothermia and may significantly improve survival with good neurological outcome in comatose patients after reestablishment of spontaneous circulation (ROSC). The starting hypothermia already in the prehospital setting or immediately after arrival to the catheterization laboratory to complement urgent coronary angiography and $\mathrm{PCl}$ seems to be a logical strategy.
\end{abstract}

Keywords: cardiac arrest, urgent coronary angiography, percutaneous coronary intervention $\mathrm{PCl}$, mild induced hypothermia, outcome

\section{Introduction}

Immediate coronary angiography in patients resuscitated from sudden cardiac arrest demonstrated angiographic evidence of coronary artery disease in $80 \%$. (1) Moreover, in patients with evidence of coronary artery disease, acute or recent coronary occlusion was demonstrated in $67 \%$. Accordingly, acute coronary thrombotic event leading to critical narrowing or complete coronary obstruction may be viewed as the main trigger of sudden cardiac arrest. There is evidence, derived from multivariate analyses of nonrandomized trials, that urgent coronary angiography followed percutaneous coronary intervention (PCl) may improve survival. (1-3) On the other hand, in comatose survivors of cardiac arrest, postresuscitation brain injury represents an additional variable with profound influence on the outcome. Severe postresuscitation brain injury leading to permanent vegetative state makes possible benefits of urgent PCl meaningless. Besides restarting the heart as soon as possible, only mild induced hypothermia has been shown to improve neurological outcome. $(4,5)$ Thus, starting hypothermia already in the prehospital setting or immediately after arrival to the catheterization laboratory to complement urgent coronary angiography and $\mathrm{PCl}$ seems to be a logical strategy.

\section{Urgent coronary angiography, $\mathrm{PCI}$ and mild induced hypothermia}

There is preliminary evidence that angiographic result of primary $\mathrm{PCl}$ in patients with ST-elevation myocardial infarction (STEMI) after reestablishment of spontaneous circulation (ROSC) is not compromised if mild induced hypothermia is used concomitantly (table 1). Moreover, there is no excess in arrhythmias and hemodynamic instability requiring more aggressive support with inotropes, vasopressors and intraaortic balloon counterpulsation. (6) There was some excess in pulmonary infections which, however did not compromise the outcome which was significantly better in hypothermia group. These findings were independently confirmed also by other investigators. (7) Recent literature search revealed 4 independent nonrandomized trials (6-9) and one case report (10) which cumulatively investigated 138 comatose survivors of cardiac arrest with STEMI (table 2). Coronary angiography was followed by $\mathrm{PCl}$ in $83 \%$. Platelat glycoprotein (GP Ilb/lla) were used in 64\% and stenting in $93 \%$. Patency of infarct related artery was reestablished in 93\%. Survival with good neurological outcome was obtained in $63 \%$ which is very good result for these sick patients.

Accordingly, urgent coronary angiography $/ \mathrm{PCl}$ and mild induced hypothermia should be incorporated in comprehensive postresuscitation intensive care protocol for the management of comatose survivors of cardiac arrest. $(3,11)$ When proportion of comatose survivors of cardiac arrest undergoing urgent coronary angiography/PCl and hypothermia increased to $77 \%$, hos- 
pital survival with good neurological outcome increased from $26 \%$ to $56 \%$.

(11) This is in accordance also with our observations in consecutive comatose survivors of out-of-hospital cardiac arrest in whom survival with good neurological recovery improved from 15\% between 1995-1997 to 40\% between 2006-2008 when treatment with urgent
$\mathrm{PCl}$ and hypothermia exceeded 70 and $90 \%$, respectively (figure 1$).(12,13)$

\section{Conclusion}

Urgent invasive coronary strategy including coronary angiography and $\mathrm{PCl}$ is feasible and safe in combination with mild induced hypothermia and may significantly improve survival with good neurological outcome in comatose patients after ROSC. Since contemporary treatment of comatose survivors of cardiac arrest is thereby becoming more complex, it should ideally be centralized to dedicated "24/7" primary $\mathrm{PCl}$ centers with well-equipped and skilled interventional cardiology facility and cardiac intensive care unit.

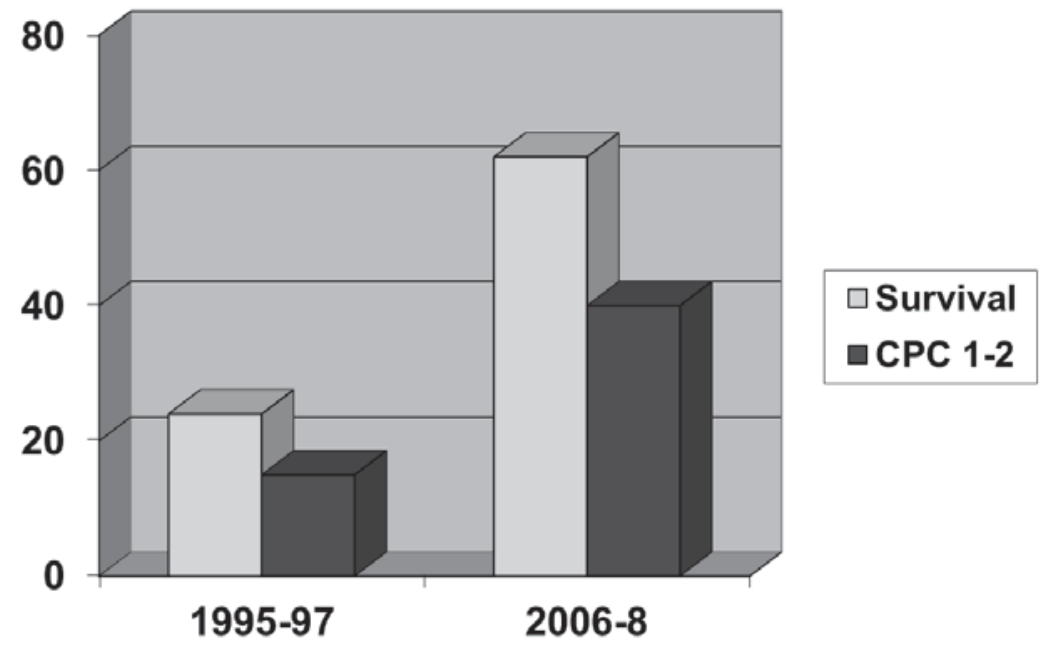

CAG,coronary angiography; CPC 1/2,cerebral performance category indicating good neurological recovery; IABP,intraaortic ballon pumping; $\mathrm{MIH}$,mild induced hypothermia; $\mathrm{PCl}$, primary percuatneous coronary intervention.

Figure 1. Difference between survival to hospital discharge and survival to hospital discharge with good neurological outcome between 1995-1997 and 2006-2008 at University Medical Center Ljubljana (Slovenia) when proportion of comatose survivors of cardiac arrest undergoing urgent coronary angiography/ $\mathrm{PCl}$ and mild induced hypothermia was significantly increased. 
Table 1. Comatose survivors of ventricular fibrillation and ST-elevation myocardial infarction undergoing primary percutaneous coronary intervention ( $\mathrm{PCl}$ ) and mild induced hypothermia compared to historical controls undergoing primary PCI but no hypothermia (Adapted from 15).

\begin{tabular}{|c|c|c|c|}
\hline & $\begin{array}{l}\text { Hypothermia } \\
(n=40)\end{array}$ & $\begin{array}{l}\text { No hypothermia } \\
(n=32)\end{array}$ & $\mathrm{p}$ \\
\hline Post PPCI TIMI 2/3,\% & 90 & 88 & .41 \\
\hline$>70 \%$ ST resolution, $\%$ & 68 & 59 & .64 \\
\hline Stent thrombosis & 2.5 & 0 & 1.0 \\
\hline Sustained VT,\% & 13 & 19 & 69 \\
\hline Repeat VF,\% & 20 & 19 & .87 \\
\hline Paroxismal AF,\% & 18 & 16 & .92 \\
\hline $\mathrm{DC} / \mathrm{EC}, \%$ & 30 & 34 & .89 \\
\hline Antiarrhytmics, \% & 33 & 53 & .13 \\
\hline $\mathrm{IABP}, \%$ & 20 & 22 & .92 \\
\hline Vasopressors,\% & 65 & 53 & .44 \\
\hline Inotropes,\% & 48 & 59 & .44 \\
\hline Peak arterial lactate, $\mathrm{mmol} / \mathrm{l}$ & $5.1+4.5$ & $5.7+4.0$ & .56 \\
\hline Peak creatinine, $\mathrm{mcmol} / \mathrm{l}$ & $160+131$ & $158+147$ & .95 \\
\hline Need for hemodialysis,\% & 7.5 & 6.5 & .80 \\
\hline Peak CRP, mg/l & $174+82$ & $184+96$ & .64 \\
\hline Positive tracheal aspirates, $\%$ & 93 & 72 & .04 \\
\hline Need for antimicrobials, $\%$ & 90 & 72 & .07 \\
\hline Hospital survival, \% & 75 & 44 & .001 \\
\hline Hospital survival with CPC 1/2,\% & 55 & 16 & .001 \\
\hline 6-months survival, \% & 68 & 38 & .021 \\
\hline 6-months survival with CPC $1 / 2$ & 53 & 19 & .007 \\
\hline
\end{tabular}

AF, atrial fibrillation; CPC 1/2, cerebral performance cathegory indicating good neurological recovery; CRP, C-reactive protein; DC, defibrillation; EC, cardioversion; IABP, intraaortic balloon pumping; PPCI TIMI- primary percutaneous coronary intervention thrombolysis in myocardial infarction; VF, ventricular fibrillation; VT, ventricular tachycardia.

Table 2. Primary percuatneous coronary intervention in comatose survivors of ventricular fibrillation and signs of STelevation acute myocardial infarction (STEMI) after reestablishement of spontaneous circulation.

\begin{tabular}{|c|c|c|c|c|c|c|c|}
\hline Author & $n$ & $\begin{array}{l}\mathrm{PPCl} \\
\mathrm{llb} / / / \mathrm{a}\end{array}$ & $\begin{array}{l}\text { GP } \\
\text { IRA }\end{array}$ & Stentin & Patent & IABP & Survival CPC 1/2 \\
\hline Knafelj (15) & 40 & 36 & 18 & 32 & 36 & 8 & 2 \\
\hline Hovdenes (17) & 50 & 36 & NA & NA & NA & 23 & 34 \\
\hline Koutouzis (19) & 1 & 1 & NA & 1 & 1 & 0 & 1 \\
\hline Wolfrum (16) & 16 & 16 & 15 & 16 & 16 & 5 & 11 \\
\hline Schefold (18) & 31 & 25 & 16 & NA & NA & NA & 19 \\
\hline Together & 138 & $\begin{array}{l}114 / 138 \\
(83 \%)\end{array}$ & $\begin{array}{c}49 / 77 \\
(64 \%)\end{array}$ & $\begin{array}{l}49 / 53 \\
(93 \%)\end{array}$ & $\begin{array}{c}53 / 57 \\
(93 \%)\end{array}$ & $\begin{array}{l}36 / 107 \\
(34 \%)\end{array}$ & $\begin{array}{l}87 / 138 \\
(63 \%)\end{array}$ \\
\hline
\end{tabular}

CPC $1 \frac{1}{2}$, cerebral performance cathegory indicating good neurological recovery; GP IIb/llla, platlet glycoprotein inhibitors; IABP, intraaortic balloon pumping; IRA, infarct related artery; NA, not avaiable; PPCl, primary percutaneous coronary intervention. 


\section{REFERENCES}

1. Spaulding CM, Joly LM, Rosenberg A, Monchi M, Weber SN, Dhainaut JF, et al. Immediate coronary angiography in survivors of out-of hospital cardiac arrest. N Engl J Med 1997;336:1629-33.

2. Werling M, Thoren AB, Axelsson C, Herlitz J. Treatment and outcome in post resuscitation care after out-of-hospital cardiac arrest when a modern therapeutic approach was introduced. Resuscitation 2007;73:40-5.

3. Dumas F, Cariou A, Manzo-Siliberman S, Grimaldi D, Vivien B, Rosencher J, et al. Immediate percutaneous coronary intervention is associated with better survival after out-of-hospital cardiac arrest: insights from the PROCAT (Parisian Region Out of Hospital Cardiac ArresT) registry. Circ Cardiovasc Interv 2010;3:200-7.

4. The Hypothermia After Cardiac Arrest (HACA) study group. Mild therapeutic hypothermia to improve the neurological outcome after cardiac arrest. N Engl J Med 2002;346:549-56

5. Bernard SA, Gray TW, Buist MD, Jones BM, Silvester W, Gutteridge G, et al. Treatment of comatose survivors of out-of-hospital cardiac arrest with induced hypothermia. N Engl J Med 2002;346:557-63.

6. Knafelj R, Radsel P, Ploj T, Noc M. Primary percutaneous coronary intervention and mild induced hypothermia in comatose survivors of ventricular fibrillation with ST-elevation acute myocardial infarction. Resuscitation 2007;74:227-34.

7. Wolfrum S, Pierau C, Radke PW, Schunkert H, Kurowski V. Mild therapeutic hypothermia in patients after out-of-hospital cardiac arrest due to acute ST-segment elevation myocardial infarction undergoing immediate percutaneous coronary intervention. Crit Care Med 2008;36:1780-6.

8. Hovdenes J, Laake JH, Aaberge L, Haugaa H, Bugge JF. Therapeutic hypothermia after out-of-hospital cardiac arrest: experiences with patients treated with percutaneous coronary intervention and cardiogenic shock. Acta Anaesthesiol Scand 2007;51:137-42.

9. Schefold J, Strom C, Joerres A, Hasper D. Mild therapeutic hypothermia after cardiac arrest and the risk of bleeding in patients with acute myocardial infarction. Int J Cardiol 2009;132:387-91.

10. Koutouzis M, Nikolaou N, Lazaris E, Kourouklis S, Kyriakides Z. Interventional hypothermia and primary percutaneous coronary intervention in a patient with anterior wall ST elevation myocardial infarction and aborted sudden death. Hellenic J Cardiol 2007;48:377-9.

11. Sunde K, Pytte M, Jacobsen D, Mangschau A, Jensen LP, Smedsrud C, et al. Implementation of a standardized treatment protocol for post resuscitation care after out-of-hospital cardiac arrest. Resuscitation 2007;73:29-39.

12. Tadel S, Horvat M, Noc M. Treatment of out-of-hospital cardiac arrest in Ljubljana - outcome report according to the "Utstein" style. Resuscitation 1998;38:169-76.

13. Tadel-Kocjancic S, Radsel P, Knafelj R, Gorjup V, Noc M. Improved hospital outcome of comatose survivors of cardiac arrest of presumed cardiac origin. Acute cardiac Care Meeting, Copenhagen, October 6-9, 2010 (in press). 